\title{
Sod1 Loss Induces Intrinsic Superoxide Accumulation Leading to p53-Mediated Growth Arrest and Apoptosis
}

\section{Kenji Watanabe ${ }^{1}$, Shuichi Shibuya ${ }^{1}$, Hirofumi Koyama ${ }^{1}$, Yusuke Ozawa ${ }^{1}$, Toshihiko Toda ${ }^{1}$, Koutaro Yokote ${ }^{2}$ and Takahiko Shimizu ${ }^{1, *}$}

1 Department of Advanced Aging Medicine, Chiba University Graduate School of Medicine, 1-8-1 Inohana, Chuo-ku, Chiba 260-8670, Japan; E-Mails: kng.wtnb@chiba-u.jp (K.W.); white10parakeets@hotmail.co.jp (S.S.); hkoyama@goo.jp (H.K.); ozawayusuke3@gmail.com (Y.O.); hik_toda@proteome.jp (T.T.)

2 Department of Clinical Cell Biology and Medicine, Chiba University Graduate School of Medicine, 1-8-1 Inohana, Chuo-ku, Chiba 260-8670, Japan; E-Mail: kyokote@faculty.chiba-u.jp

* Author to whom correspondence should be addressed; E-Mail: shimizut@chiba-u.jp; Tel.: +81-43-222-7171; Fax: +81-43-226-2095.

Received: 18 March 2013; in revised form: 8 May 2013 / Accepted: 9 May 2013 /

Published: 24 May 2013

\begin{abstract}
Oxidative damages induced by a redox imbalance cause age-related changes in cells and tissues. Superoxide dismutase (SOD) enzymes play a major role in the antioxidant system and they also catalyze superoxide radicals $\left(\mathrm{O}_{2}{ }^{-}{ }^{-}\right)$. Since the loss of cytoplasmic SOD (SOD1) resulted in aging-like phenotypes in several types of mouse tissue, SOD1 is essential for the maintenance of tissue homeostasis. To clarify the cellular function of SOD1, we investigated the cellular phenotypes of Sod1-deficient fibroblasts. We demonstrated that Sodl deficiency impaired proliferation and induced apoptosis associated with $\mathrm{O}_{2}{ }^{--}$accumulation in the cytoplasm and mitochondria in fibroblasts. Sod1 loss also decreased the mitochondrial membrane potential and led to DNA damage-mediated p53 activation. Antioxidant treatments effectively improved the cellular phenotypes through suppression of both intracellular $\mathrm{O}_{2}{ }^{--}$accumulation and p53 activation in Sod1-deficient fibroblasts. In vivo experiments revealed that transdermal treatment with a vitamin $\mathrm{C}$ derivative significantly reversed the skin thinning commonly associated with the upregulated p53 action in the skin. Our findings revealed that intrinsic $\mathrm{O}_{2}{ }^{-}$ accumulation promoted p53-mediated growth arrest and apoptosis as well as mitochondrial disfunction in the fibroblasts.
\end{abstract}


Keywords: reactive oxygen species; superoxide dismutase; vitamin C; p53; apoptosis

\section{Introduction}

Reactive oxygen species (ROS) are mainly generated from mitochondrial respiration and they non-specifically oxidize cellular molecules including proteins, nucleic acid, and lipids, resulting in oxidative damage in organisms [1]. Redox balance is physiologically regulated through the production and degradation of ROS by antioxidant systems to protect cells from oxidative damage. Extrinsic excess ROS induces the DNA damage response (DDR) associated with oxidative DNA damage and promotes a canonical ATM-p53 cascade that regulates the cell fate [2]. ROS also dysregulates mitochondrial function through a reduction of membrane potential and respiration [3]. In this context, maintenance of redox balance in cells plays an important role in the determination of cellular fate and function, including apoptosis, cell cycle arrest, differentiation, and energy metabolism [4].

Superoxide dismutase (SOD) is one of the major antioxidant enzymes that catalyzes the conversion of superoxide radicals $\left(\mathrm{O}_{2}{ }^{-}\right)$to hydrogen peroxide $\left(\mathrm{H}_{2} \mathrm{O}_{2}\right)$ and $\mathrm{O}_{2}$ [5]. SOD1 and SOD2 are ubiquitously expressed in tissues, and localized in the cytoplasm and mitochondria, respectively. Our previous studies demonstrated that $\operatorname{Sod} 1$-deficient $\left(\operatorname{Sod}_{1}^{--}\right)$mice show various aging-like pathologies, such as: age-related macular degeneration [6], fatty deposits in the liver [7], skin atrophy [8], osteoporosis [9], deterioration of Alzheimer's disease (AD) [10], luteal degeneration [11], and lacrimal degeneration [12]. Furthermore, several groups have reported that $\operatorname{Sod}^{-/}$deficiency also induced: hepatocellular carcinoma [13], muscle atrophy [14], hemolytic anemia [15] in mice, and poor growth rate in cells [16]. These observations indicate that $S o d 1^{-/-}$mice have the potential to be a valuable animal model for investigating human age-related diseases.

In the present study, we investigated the cellular phenotypes of $\operatorname{Sod} 1^{-/-}$fibroblasts to clarify the biological significance of Sodl and the pathophysiological role of intracellular $\mathrm{O}_{2}^{-{ }^{-}}$. We also investigated the involvement of the DDR and p53 activation under an intrinsic $\mathrm{O}_{2}{ }^{--}$accumulation. Finally, we have discussed the anti-aging effect of an antioxidant administered both in vitro and in vivo.

\section{Results and Discussion}

\subsection{Sod1 Deficiency Induced Apoptotic Cell Death with Increased Superoxide Accumulation in Fibroblasts}

In order to investigate the biological significance of the SOD1 enzyme in cells, we analyzed the cellular phenotypes of Sod1-deficient primary dermal fibroblasts. Western blot analysis revealed the complete loss of the SOD1 protein in Sod1 $1^{-/}$cells (Figure 1A). Interestingly, the concentration of the SOD2 protein, an alternative intracellular SOD localized in mitochondria, remained unchanged in Sod $1^{-/-}$cells, suggesting that SOD1 loss did not induce the compensatory expression of SOD2 protein in the cells (Figure 1A). Likewise, expression levels of other antioxidant enzymes, including glutathione peroxidase 1 and catalase, were not upregulated in $\operatorname{Sod}^{-/-}$cells (data not shown). In cell 
culture experiments, $\mathrm{Sod} 1^{-/-}$fibroblasts showed the marked loss of cell viability under a $20 \% \mathrm{O}_{2}$ concentration (Figure 1B). We next analyzed the incorporation of BrdU to measure the proliferative ability of the $\operatorname{Sodl}^{-/}$fibroblasts. As shown in Figure 1C, Sodl loss significantly impaired the incorporation of BrdU at culture day 2, indicating the disturbance of cell proliferation. Furthermore, Sod1 depletion markedly increased the expression of cleaved caspase3 (Figure 1D) and annexin V positive cells (Figure 1E,F), indicating the induction of apoptotic cell death. These results demonstrated that Sodl deficiency induced proliferative decline and apoptosis in dermal fibroblasts.

Figure 1. Sodl deficiency induces growth arrest and cell death in primary dermal fibroblasts. (A) SOD1 and SOD2 expression in $S o d 1^{-/-}$and $S o d 1^{+/+}$fibroblast. (B) The cell numbers of $\operatorname{Sodl}^{-/-}$and $\operatorname{Sod} 1^{+/+}$fibroblasts $(n=3)$ were counted at the times indicated; (C) The cell viabilities of $\operatorname{Sod1}^{-/-}$and $\operatorname{Sod} 1^{+/+}$fibroblasts $(n=3)$ were measured by BrdU incorporation; (D) Apoptosis in $\operatorname{Sod1}^{-/-}$and Sod1 $1^{+/+}$fibroblasts was analyzed by western blotting with an anti-cleaved caspase 3 antibody. To induce apoptosis, the cells were treated with $12 \mu \mathrm{M}$ camptothecin (CPT) for $12 \mathrm{~h}$; (E) Apoptosis in Sod1 ${ }^{-/-}$and Sod1 ${ }^{+/+}$fibroblasts was analyzed by flow cytometry with propidium iodide (PI) and Annexin V; (F) The relative percentage of Annexin $\mathrm{V}$ positive cells in $\operatorname{Sodl}^{-/-}$and $\operatorname{Sod} 1^{+/+}$fibroblasts $(n=3)$. These data indicate the mean $\pm \mathrm{SD} ; * * p<0.01, * * * p<0.001$.

A

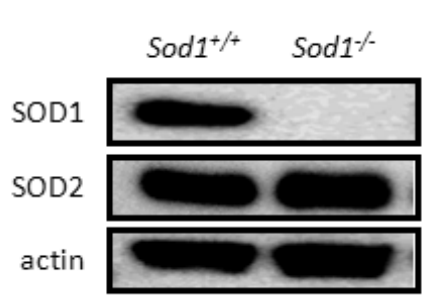

D

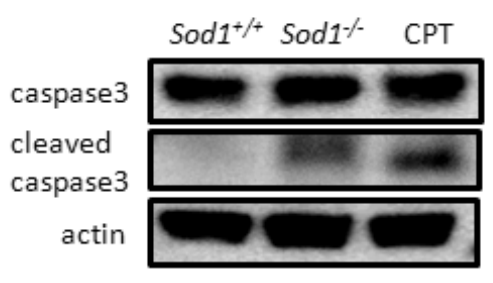

B

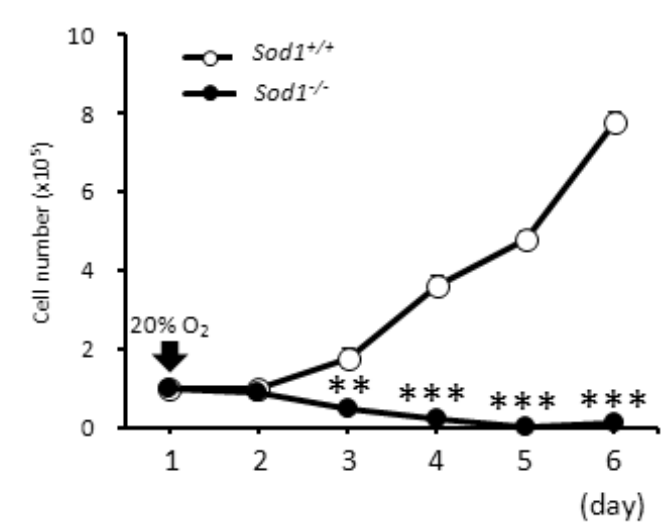

$\mathrm{E}$

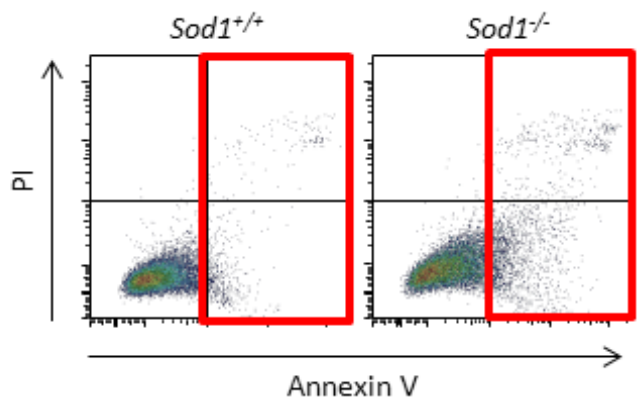

C

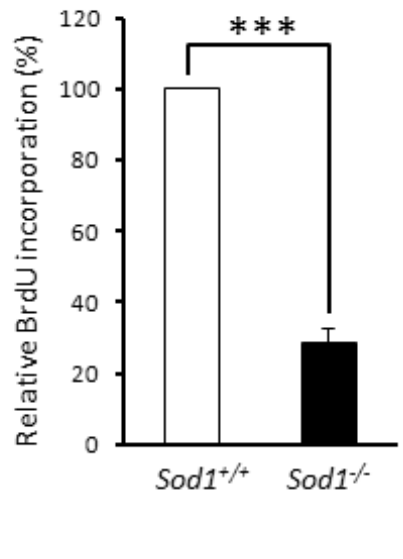

F

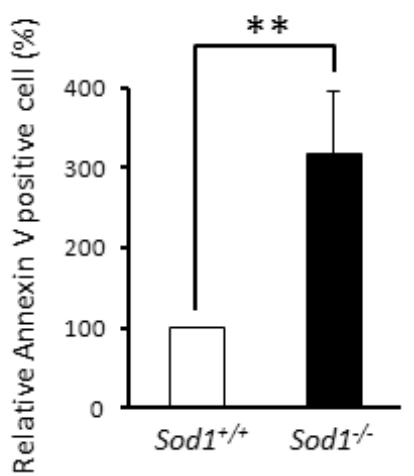

Because SOD1 catalyzes $\mathrm{O}_{2}{ }^{--}$to $\mathrm{H}_{2} \mathrm{O}_{2}$ and $\mathrm{O}_{2}$ in the cytoplasm, SOD1 loss results in increased cytoplasmic $\mathrm{O}_{2}{ }^{--}$accumulation in cells. In order to evaluate the $\mathrm{O}_{2}{ }^{--}$imbalance by SOD1 deficiency, we measured the $\mathrm{O}_{2}{ }^{--}$level using flow cytometry and a specific fluorescent dye for cytoplasmic $\mathrm{O}_{2}{ }^{--}$, dihydroethidium (DHE). The DHE staining revealed a significant, 2.7-fold enhancement in the 
cytoplasmic $\mathrm{O}_{2}^{--}$level in Sod1 ${ }^{-/-}$compared to $\mathrm{Sodl}^{+/+}$fibroblasts (Figure 2A). Interestingly, MitoSOX staining, which is a specific fluorescent dye for $\mathrm{O}_{2}{ }^{--}$in mitochondria, also revealed a significant, 4-fold enhancement in the mitochondrial $\mathrm{O}_{2}{ }^{--}$level in Sod1 ${ }^{-/-}$compared to Sod1 $1^{+/+}$ fibroblasts (Figure 2B), These results suggested that SOD1 regulates the $\mathrm{O}_{2}{ }^{--}$balance in both the cytoplasm and the mitochondria.

Figure 2. Sod1 loss induces $\mathrm{O}_{2}^{--}$generation and mitochondrial dysfunction in fibroblasts. $(\mathbf{A}, \mathbf{B})$ Intracellular $\mathrm{O}_{2}{ }^{--}$was measured by flow cytometry with dihydroethidium and MitoSOX in $\operatorname{Sod}^{-/-}$and $\operatorname{Sod} 1^{+/+}$fibroblasts $(n=3)$. These data indicate the mean $\pm \mathrm{SD}$; $* p<0.05, * * p<0.01$.

A

DHE

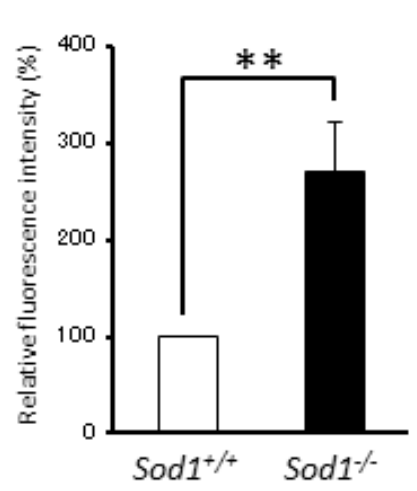

B

MitoSOX

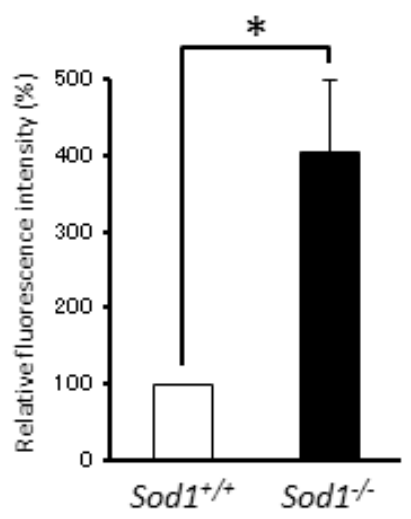

\subsection{Sod1 Loss Caused p53 Upregulation Associated with Mitochondrial Dysfunction in Fibroblasts}

Since mitochondrial ROS induces the loss of mitochondrial membrane potential $(\Delta \Psi \mathrm{m})[3]$, we measured $\Delta \Psi \mathrm{m}$ using a JC-1 dye in $S o d 1^{-/-}$fibroblasts. As expected, Sod $1^{-/}$fibroblasts showed a 2.2-fold increase in the number of mitochondria with low $\Delta \Psi \mathrm{m}$ (Figure 3A,B). Since decreased $\Delta \Psi \mathrm{m}$ induces apoptosis [17], our findings suggested that $\mathrm{O}_{2}{ }^{--}$accumulation in mitochondria resulting from Sod1 deficiency results in apoptosis through mitochondrial dysfunction.

Tumor suppressor p53 plays a crucial role in various cellular functions such as apoptosis, cell cycle arrest, energy metabolism, and senescence [4]. Since DNA damage caused by excess irradiation and ROS stimulates upregulation and phosphorylation of p53 via DDR resulting in apoptosis [18], we analyzed the p53 level in Sod1 ${ }^{-/-}$fibroblasts. Western blot analysis clearly demonstrated markedly increased protein levels and phosphorylation at $\mathrm{Ser}^{18}$ of $\mathrm{p} 53$ in $\operatorname{Sodl}^{-/-}$fibroblasts (Figure 3C). Quantitative PCR analysis revealed that $S o d 1^{-/-}$deficiency had a tendency to increase p53 mRNA levels, but not significantly (Figure 3D), suggesting that p53 upregulation is not only regulated by mRNA levels but may be due to p53 stabilization in Sod1 ${ }^{-/-}$fibroblasts. Furthermore, we found phosphorylated $\mathrm{H} 2 \mathrm{AX}$ at $\operatorname{Ser}^{139}(\gamma \mathrm{H} 2 \mathrm{AX})$, a DNA damage marker, and identified the upregulation of p21, a target gene of p53 (Figure 3C). These data indicated that the DNA damage caused by Sod1 deficiency also induced a proliferative defect and apoptosis via p53 activation. 
Figure 3. Sod1 loss induces mitochondrial dysfunction in fibroblasts. (A) The loss of mitochondrial membrane potential $(\Delta \Psi \mathrm{m})$ was measured by flow cytometry with JC-1; (B) The relative percentage of mitochondria with low $\Delta \Psi \mathrm{m}$ in $\operatorname{Sodl}^{-/-}$and $\operatorname{Sodl}^{+/+}$ fibroblasts $(n=4)$; $(\mathbf{C})$ Western blotting of DNA damage response proteins such as p53, p53 phosphorylation at $\operatorname{Ser}^{18}, \gamma \mathrm{H} 2 \mathrm{AX}$ and p21 in Sod1 ${ }^{-/-}$and Sod1 $1^{+/+}$fibroblasts; (D) p53 mRNA expression was analyzed by quantitative PCR in $S_{o d 1^{-/-}}$and $S_{o d l^{+/+}}$fibroblasts $(n=4)$. These data indicate the mean $\pm \mathrm{SD} ;{ }^{*} p<0.05$.

A

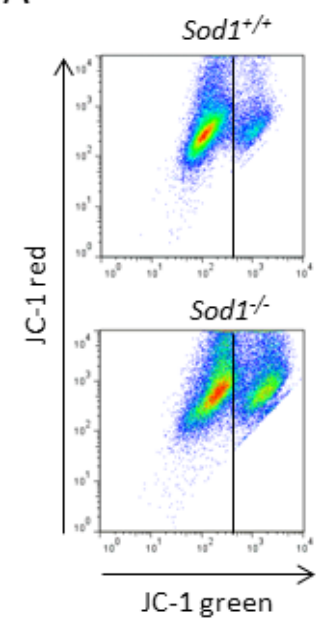

B

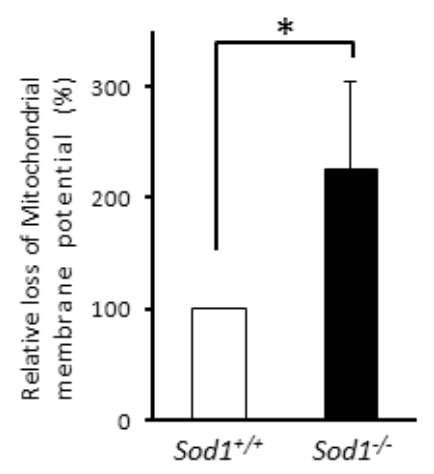

C

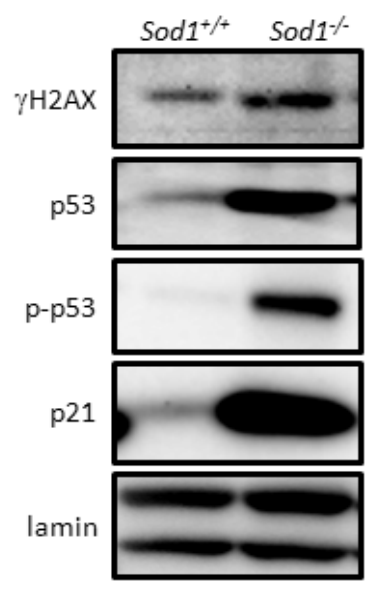

D

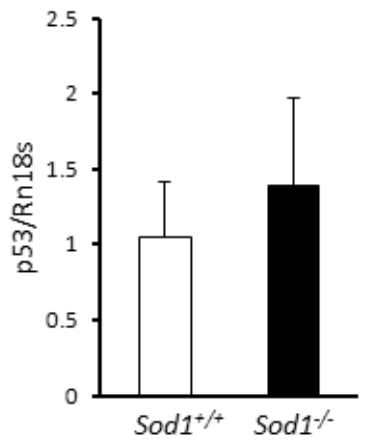

\subsection{A Vitamin C Derivative Rescued Viability of Sod1-Deficient Fibroblasts through a Suppression of} $\mathrm{O}_{2}{ }^{--}$Generation and p53 Upregulation

In vitro data indicate that the suppression of intracellular $\mathrm{O}_{2}{ }^{--}$generation and p53 activation by antioxidants can improve the cellular phenotypes of $S o d 1^{-/-}$fibroblasts. Thus, we evaluated whether antioxidants could protect the cellular phenotypes in $S o d 1^{-/-}$fibroblasts. To investigate the rescue activity of a vitamin C (VC) derivative, L-ascorbyl 2-phosphate 6-palmitate (APPS), we cultured Sod1 null fibroblasts in the presence of APPS. The APPS treatment $(10 \mu \mathrm{M})$ significantly increased the cell numbers of $\mathrm{Sod}^{-/-}$fibroblasts at culture day 3 under a $20 \% \mathrm{O}_{2}$ condition (Figure 4A). At culture days 6 and 8, Sod1 $1^{-/-}$fibroblasts proliferated markedly in the presence of APPS compared to absence of APPS (Figure 4A). Finally, Sod $1^{-/-}$fibroblasts with APPS propagated to confluence in a culture dish under a $20 \% \mathrm{O}_{2}$ condition (data not shown), indicating that the $\mathrm{VC}$ derivative notably enhanced the viability of $\mathrm{Sod1}^{-/-}$fibroblasts. Next, we measured the intracellular $\mathrm{O}_{2}{ }^{--}$levels in $\mathrm{Sodl}^{-/-}$fibroblasts in the presence of APPS to confirm the anti-oxidative ability of APPS. Treatment with APPS completely suppressed the intracellular $\mathrm{O}_{2}{ }^{--}$level in $\mathrm{Sodl}^{-/-}$fibroblasts at culture day 2 (Figure 4B), indicating the effective anti-oxidant activity of APPS.

To investigate the downstream molecular events by Sodl deficiency, we assessed the p53 expression levels in APPS-treated Sod1 $1^{-/}$fibroblasts. Treatment with APPS significantly inhibited p53 upregulation and phosphorylation at $\operatorname{Ser}^{18}$ (Figure 4C). We also cultured Sod $1^{-/-}$fibroblasts in the presence of another antioxidant, $N$-acetyl cysteine (NAC). As expected, treatment with NAC significantly accelerated cell viability and suppressed the intracellular $\mathrm{O}_{2}{ }^{--}$level in $\mathrm{Sod}^{-/-}$fibroblasts (Figure 4D,E). Furthermore, to exclude the direct action of APPS on p53 expression, we investigated 
the inhibition ability of APPS on DNA damage-induced p53 upregulation. When NIH3T3 cells were cultured with camptothecin (CPT), a DNA damage-inducer, p53 protein was significantly upregulated in a dose-dependent manner (Figure 4F). The APPS treatment, however, failed to inhibit p53 upregulation by CPT treatment, indicating that APPS is not able to suppress p53 expression in response to DNA damage. These results revealed that a VC derivative effectively normalized the cellular viability, $\mathrm{O}_{2}{ }^{--}$accumulation, and p53 upregulation via the direct anti-oxidant activity in Sod $1^{-/-}$fibroblasts.

Figure 4. A VC derivative rescues cellular phenotypes in $S o d 1^{-/}$fibroblasts. (A) The cell numbers of $\mathrm{Sodl}^{-/-}$fibroblasts treated with or without $10 \mu \mathrm{M}$ APPS was counted at the time indicated $(n=3)$; (B) The relative $\mathrm{O}_{2}{ }^{--}$level in $S o d 1^{-/-}$fibroblasts treated with $10 \mu \mathrm{M}$ APPS was measured by DHE $(n=3)$; (C) Western blot analysis of p53 and p53 phosphorylation at $\operatorname{Ser}^{18}$ in $\operatorname{Sod}^{-/-}$fibroblasts treated with $10 \mu \mathrm{M}$ APPS; (D) The cell viabilities of $\operatorname{Sodl}^{-/-}$and $\operatorname{Sodl}^{+/+}$fibroblasts $(n=3)$ were measured at culture day 2 by Cell Counting Kit-8; (E) Intracellular $\mathrm{O}_{2}{ }^{--}$level in Sod $1^{-/-}$fibroblasts treated with $1 \mathrm{mM}$ NAC was measured by DHE. The scale bar represents $100 \mu \mathrm{m}$; (F) Western blot analysis of p53 in NIH3T3 with or without $20 \mu \mathrm{M}$ APPS. To induce DDR response, the cells were treated with CPT for $4 \mathrm{~h}$. These data indicate the mean $\pm \mathrm{SD} ;{ }^{*} p<0.05$, $* * p<0.01$, *** $p<0.001$.

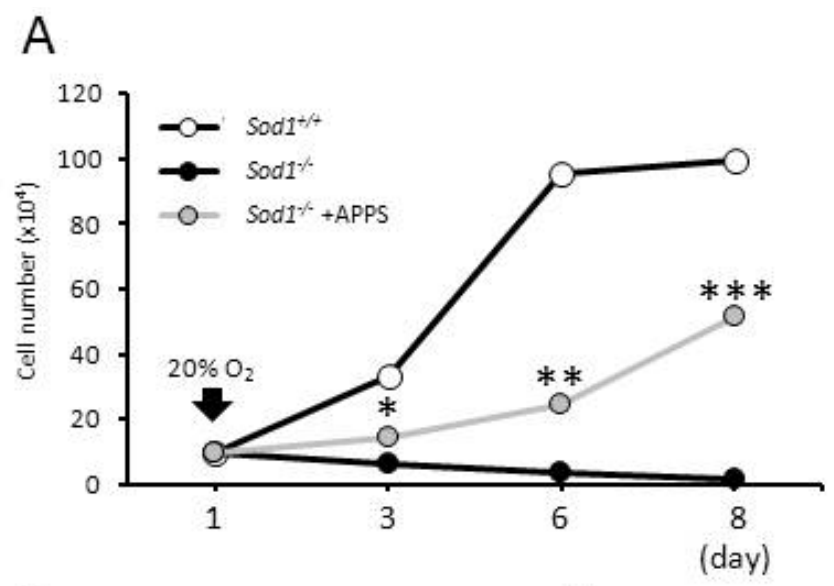

B

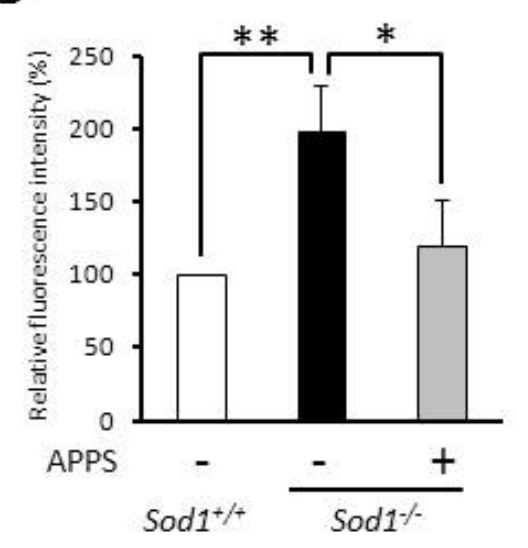

C

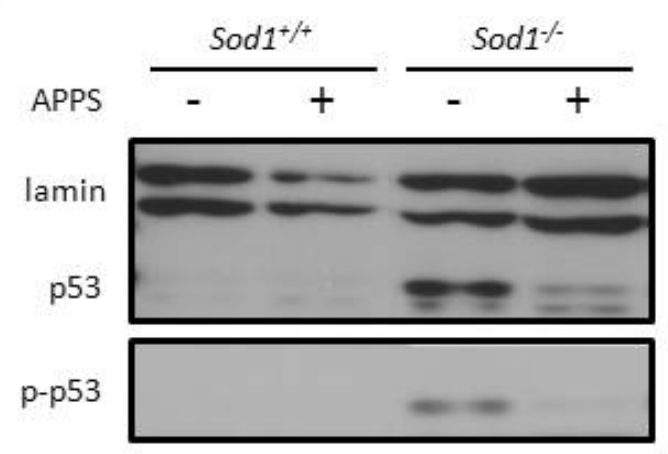


Figure 4. Cont.

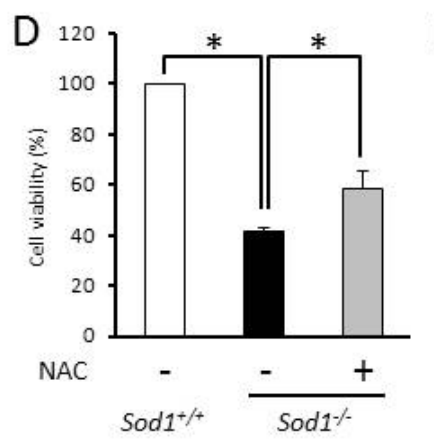

$E$
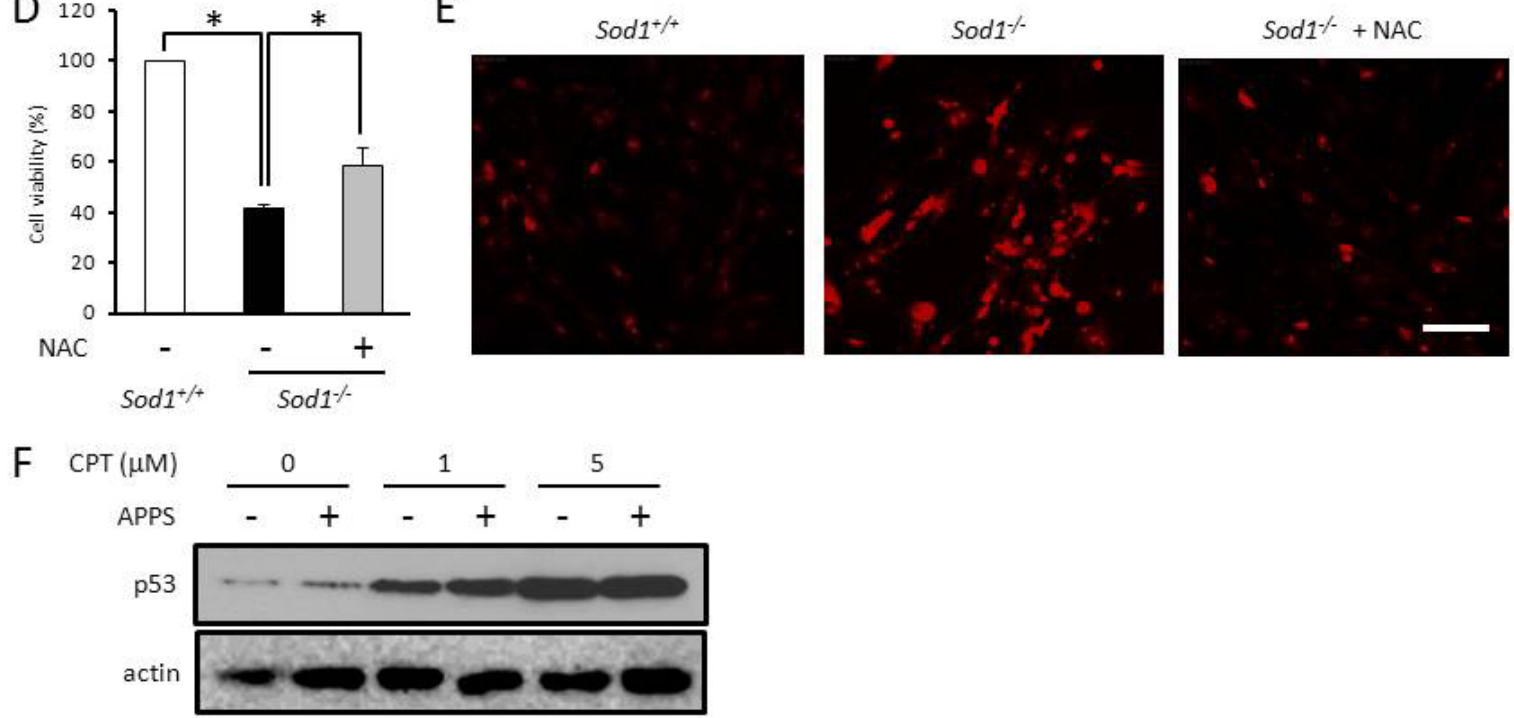

\subsection{A Vitamin C Derivative Treatment Reversed Skin Atrophy Induced by Sod1 Loss in Vivo}

We have previously reported that transdermal treatment with APPS reverses skin thinning in Sod $1^{-/-}$mice $[8,19]$. Treatment with APPS also significantly reduced lipid peroxidation in the skin of Sod $1^{-/-}$mice [19]. In the present study, we confirmed the beneficial effects of transdermal APPS treatment on skin atrophy in $S o d 1^{-/-}$mice (Figure 5A). In order to elucidate the rescue mechanism of APPS on skin pathology in Sod1 ${ }^{-/-}$mice, we measured p53 expression using quantitative PCR. As shown in Figure 5B, treatment with APPS remarkably reduced p53 expression in the skin of Sod1 $1^{-/}$ mice compared to non-treated $\mathrm{Sodl}^{-/-}$mice, suggesting that the anti-oxidant activity of APPS normalized skin pathologies by suppressing $\mathrm{O}_{2}{ }^{--}$-mediated $\mathrm{p} 53$ activation in vivo.

Figure 5. A VC derivative rescues skin phenotypes in $\operatorname{Sod} 1^{-/}$mice. (A) The hematoxylin

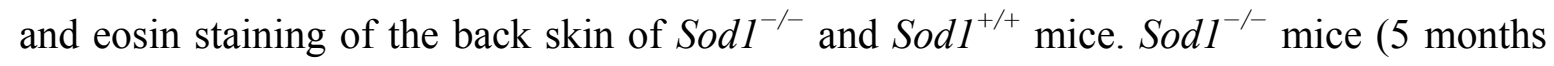
old) were transdermally treated with $1 \%$ APPS for 4 weeks. The scale bar represents $100 \mu \mathrm{m}$; (B) p53 mRNA expression was analyzed by quantitative PCR in skin tissues with or without APPS treatment $(n=6-7)$. These data indicate the mean $\pm \mathrm{SD} ; * p<0.05$.

A

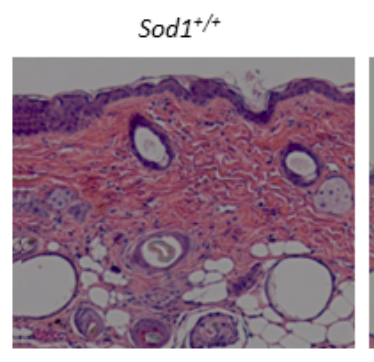

Sod $1 \%$

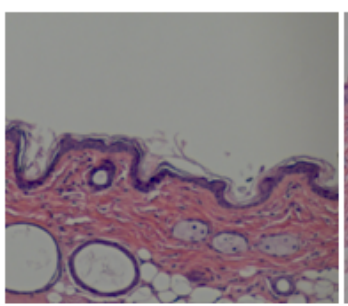

Sod $1 \%+1 \%$ APPS

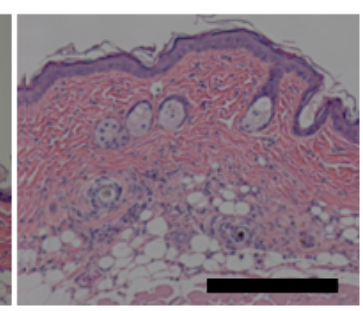

B

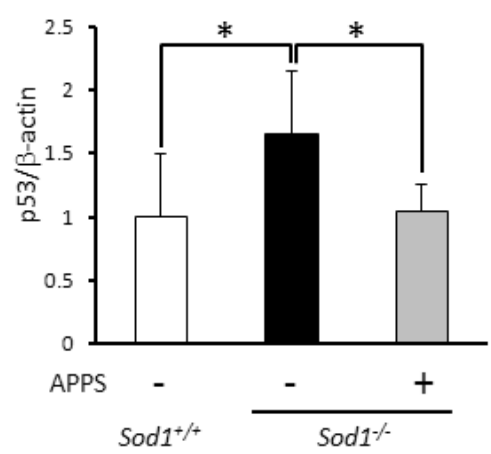




\subsection{Discussion}

In the present study, we demonstrated that $\operatorname{Sod}^{-/-}$fibroblasts showed decreased proliferative ability and increased apoptosis (Figure 1). Furthermore, Sodl loss induced $\mathrm{O}_{2}{ }^{--}$accumulation in both the cytoplasm and the mitochondria (Figure 2). Okado-Matsumoto reported that Sod1 is distributed in the cytoplasm and in the intermembrane space of mitochondria [5] and Muller et al. found that complex III released $\mathrm{O}_{2}{ }^{--}$to both sides of the inner membrane in mitochondria isolated from skeletal muscles [20]. Recently, Jang et al. also reported increased ROS generated from isolated mitochondria in the skeletal muscle of Sod $1^{-/-}$mice [21], suggesting that Sod1 physiologically regulates not only cytoplasmic $\mathrm{O}_{2}{ }^{--}$generation, but also mitochondrial $\mathrm{O}_{2}{ }^{--}$release. In our preliminary experiments, we demonstrated that $\mathrm{Sod}^{-/-}$fibroblasts showed an increased $\mathrm{O}_{2}{ }^{--}$accumulation in the mitochondria and in the cytoplasm, resulting in decreased proliferation. Interestingly, Sod 2 deficiency did not induce apoptosis in spite of increased $\mathrm{O}_{2}^{--}$accumulation in the fibroblasts. Taken together, these results suggested that Sod1 might protect from the apoptosis induced by intracellular $\mathrm{O}_{2}{ }^{--}$accumulation in fibroblasts.

Since oxidative DNA damage induced by such irritants as irradiation and chemicals promotes p53 upregulation and phosphorylation via a canonical ATM-p53 cascade [2], we investigated DDR such as phosphorylated $\mathrm{H} 2 \mathrm{AX}(\gamma \mathrm{H} 2 \mathrm{AX})$ and $\mathrm{p} 53$ activation. As expected, Sod1 ${ }^{-/-}$fibroblasts showed increased $\gamma \mathrm{H} 2 \mathrm{AX}$ with upregulation and phosphorylation of $\mathrm{p} 53$ at $\mathrm{Ser}^{18}$ (Figure 3C), whose residue is phosphorylated by ATM [2]. Moreover, p21, a p53 target gene, was significantly upregulated in Sod1-deficient fibroblasts (Figure 3C), thus suggesting that intracellular $\mathrm{O}_{2}{ }^{--}$accumulation stimulated the canonical DDR cascade including p53 activation leading to growth arrest and apoptosis in Sod1 $1^{-/-}$ fibroblasts. Accumulating evidence demonstrates that cellular p53 levels are primarily regulated by ubiquitin-mediated proteasomal degradation [22]. ATM phosphorylates both p53 at Ser $^{15}$ (mouse $\mathrm{Ser}^{18}$ ) and MDM2, an endogenous E3-ligase for $\mathrm{p} 53$, at $\mathrm{Ser}^{395}$, resulting in an impairment of MDM2-mediated p53 degradation [22]. Since ROS-induced DDR promotes ATM activity, ATM-mediated MDM2 phosphorylation may stabilize p53 levels in Sod1 $1^{-/}$cells (Figure 3C). In contrast, Gajjar et al. recently reported that p53 mRNA-MDM2 interaction controls MDM2 nuclear trafficking and p53 activation following DNA damage. They demonstrated that ATM-dependent phosphorylation of MDM2 at $\mathrm{Ser}^{395}$ resulted in its recruitment to $553 \mathrm{mRNA}$, thereby stimulating p53 upregulation [23,24]. Thus, DDR-mediated p53 mRNA-MDM2 interaction may increase p53 mRNA in $\mathrm{Sodl}^{-/-}$skin tissues (Figure 5B). Further analyses are therefore needed to clarify the molecular mechanism of the upregulation of p53 in Sod1-deficient mice.

Interestingly, Sod $1^{-/-}$fibroblasts also showed mitochondrial $\mathrm{O}_{2}{ }^{--}$accumulation and low $\Delta \Psi \mathrm{m}$ (Figure 3A,B). Since excess ROS impairs $\Delta \Psi \mathrm{m}$ [25], the cytoplasmic $\mathrm{O}_{2}{ }^{--}$accumulation caused by Sod1 deficiency may induce the loss of $\Delta \Psi \mathrm{m}$ resulting in the $\mathrm{O}_{2}{ }^{--}$accumulation in the mitochondria. Alternatively, since mitochondrial ROS also directly impairs $\Delta \Psi \mathrm{m}$ [3], concomitant $\mathrm{O}_{2}{ }^{--}$accumulation in the mitochondria may cause decreased $\Delta \Psi \mathrm{m}$. In any case, $\mathrm{O}_{2}{ }^{--}$-mediated $\Delta \Psi \mathrm{m}$ decline may cause apoptosis. Recently, Jiang et al. reported that p53 repressed the expression of TCA cycle-associated malic enzymes ME1 and ME2 in cells [26]. Since both malic enzymes are important for NADPH production, lipogenesis, and glutamate metabolism, the upregulation of p53 may also directly impair mitochondrial function via ME1 and ME2 repression leading to $\triangle \Psi \mathrm{m}$ decline. 
In a mouse model, p53 activation (p53m allele) by genetic engineering induces accelerated aging including skin atrophy [27]. Gannon et al. reported that Mdm2 loss in keratinocytes induced p53 upregulation resulting in epidermal stem cell senescence and premature aging phenotypes in mice [28]. In skin tissue, p53 also plays a crucial role in cellular fate and homeostasis. In the present study, we demonstrated that Sod1 loss induced p53 upregulation in the fibroblasts and the skin due to intracellular $\mathrm{O}_{2}{ }^{--}$accumulation. We also demonstrated that antioxidants effectively rescued $\mathrm{O}_{2}{ }^{--}$-p53 mediated cellular and skin pathologies in vitro and in vivo. These data indicate the possibility that antioxidant treatment is a promising strategy to delay skin aging by remarkably reducing the p53 upregulation in the skin.

It is widely known that $\mathrm{VC}$ is a soluble vitamin and an essential cofactor for post-translational modifications in collagen formation [29]. We previously reported that the oral administration of VC significantly improved low-turnover osteoporosis [9] as well as reduced behavioral deficits in the AD model mice [30]. However, the oral administration of VC failed to improve skin atrophies of Sod1 $1^{-/}$ mice (unpublished results), indicating the low bioavailability and stability of VC in the skin tissues. Since VC exhibits both low stability and liposolubility, it is difficult to transdermally absorb into the skin. Actually, we showed that a transdermal treatment of VC itself failed to improve the skin atrophy of Sod1 $1^{-/}$mice [19]. To increase the stability and liposolubility of VC, various VC derivatives were developed for dermatologic application. One of the VC derivatives, APPS, is conjugated to a phosphate group and a long hydrophobic chain to enhance its stability and liposolubility. Transdermal treatment with APPS effectively normalized skin thickness in Sod1 ${ }^{-/-}$mice through the suppression of oxidative damage and p53 upregulation (Figure 5). Treatment with APPS in wild-type mice showed no adverse effects in the skin tissues. Therefore, VC derivatives, including APPS, are powerful anti-aging agents for skin through an antioxidant effect.

\section{Experimental Section}

\subsection{Animals}

Sod $1^{-/}$mice were purchased from the Jackson Laboratory (Bar Harbor, ME, USA). All of the genotypes of Sod1 mice were assessed by PCR using genomic DNA isolated from the tail tip as described previously [9]. The animals were housed under a $12 \mathrm{~h}$ light/dark cycle and were fed ad libitum. The experimental procedures were approved by the Animal Care and Use Committee of Chiba University.

\subsection{Cell Culture}

The skin tissue specimens were dissected from 5-day-old Sod1 ${ }^{-/-}$neonates. The primary dermal fibroblasts were isolated by dissociation in $0.2 \%$ collagenase type 2 (Worthington Biochemical Corporation, Lakewood, NJ, USA) at $37{ }^{\circ} \mathrm{C}$ for $60 \mathrm{~min}$. The cells were cultured in $\alpha$-MEM (Life Technologies Corporation, Carlsbad, CA, USA) supplemented with $20 \%$ fetal bovine serum (FBS), $100 \mathrm{unit} / \mathrm{mL}$ penicillin, and $0.1 \mathrm{mg} / \mathrm{mL}$ streptomycin at $37{ }^{\circ} \mathrm{C}$ in a humidified incubator with $5 \% \mathrm{CO}_{2}$ and $1 \% \mathrm{O}_{2}$. During experiments, the cells were cultured under a $20 \% \mathrm{O}_{2}$ condition. The cells were treated with $10 \mu \mathrm{M}$ L-ascorbyl 2-phosphate 6-palmitate (APPS, Showa Denko K. K., Tokyo, Japan) at the indicated times. Cell viability was measured by cell proliferation ELISA, BrdU (Roche Diagnostics K.K., Tokyo, Japan) or Cell Counting Kit-8 (Dojindo Laboratories, Kumamoto, Japan) according to 
the manufacturer's instructions. NIH3T3 cells (RCB1862) were cultured in DMEM (Sigma-Aldrich inc., St. Louis, MO, USA) containing 10\% FBS, $100 \mathrm{unit} / \mathrm{mL}$ penicillin, and $0.1 \mathrm{mg} / \mathrm{mL}$ streptomycin. The cells were treated with $20 \mu \mathrm{M}$ APPS for $24 \mathrm{~h}$. To induce DNA damage, NIH3T3 cells were treated with camptothecin (Enzo Life Sciences Inc., Tokyo, Japan) for $4 \mathrm{~h}$.

\subsection{Western Blotting}

The fibroblasts were lysed in an NP-40 lysis buffer [50 mM Tris-HCl, $\mathrm{pH} 8.0 ; 150 \mathrm{mM} \mathrm{NaCl} ; 1 \%$ NP-40; protease inhibitor (1 $\mathrm{mM}$ phenylmethanesulfonylfluoride and $2 \mu \mathrm{g} / \mathrm{mL}$ aprotinin); and phosphatase inhibitors $(1 \mathrm{mM}$ sodium fluoride and $1 \mathrm{mM} \beta$-glycerophosphate $2 \mathrm{Na})$ ]. The samples were placed at $4{ }^{\circ} \mathrm{C}$ for $20 \mathrm{~min}$, vortexed, and centrifuged at 15,000 rpm for $10 \mathrm{~min}$. The supernatants were collected, and $20 \mu \mathrm{g}$ of each sample were loaded onto a 10\% SDS-polyacrylamide gel. Antibodies against SOD1 (1:500, ADI-SOD-100-F, Enzo Life Sciences), SOD2 (1:500, ADI-SOD-200-F, Enzo Life Sciences), caspase3 (1:500, \#9665, Cell Signaling Technology, Inc. MA, USA), cleaved caspase3 (1:500, \#9664S, Cell Signaling Technology), p53 (1:200, \#2524S, Cell Signaling Technology), human phospho-p53 at $\operatorname{Ser}^{15}$ (mouse Ser ${ }^{18}$ ) (1:200, \#9284S, Cell Signaling Technology), and actin (1:1000, A2066, Sigma, St. Louis, MO, USA), and lamin A/C (1:500, \#2035, Cell Signaling Technology) were used.

\subsection{Flow Cytometry}

The accumulation of intracellular $\mathrm{O}_{2}{ }^{--}$was detected using dihydroethidium (DHE, Life Technologies Corporation, Gaithersburg, MD, USA) and MitoSOX (Life Technologies Corporation), which are specific detectors of the $\mathrm{O}_{2}{ }^{--}$concentration in the cytoplasm and mitochondria, respectively [31]. To measure $\Delta \Psi \mathrm{m}$, the cells were stained with JC-1 dye, a $\Delta \Psi \mathrm{m}$ probe (Life Technologies Corporation). The cells were incubated with $10 \mu \mathrm{M}$ DHE, $5 \mu \mathrm{M}$ MitoSOX, or $10 \mu \mathrm{M}$ JC-1 for $30 \mathrm{~min}$ at $37^{\circ} \mathrm{C}$. Following incubation, the cells were trypsinized and resuspended in PBS. Apoptosis was measured using an FITC Annexin V Apoptosis Detection Kit I (BD Biosciences, San Jose, CA, USA) according to the manufacturer's instructions. The fluorescence intensities were assessed using a flow cytometer (BD FACSCanto ${ }^{\mathrm{TM}}$ II, BD Biosciences, San Jose, CA, USA).

\subsection{Histology}

The fibroblasts were pre-incubated for $24 \mathrm{~h}$ with $1 \mathrm{mM} \mathrm{N}$-acetylcysteine (NAC). The accumulation of intracellular $\mathrm{O}_{2}{ }^{--}$was detected using DHE. The cells were incubated with $10 \mu \mathrm{M}$ DHE for 30 min at $37{ }^{\circ} \mathrm{C}$. Following incubation, the cells were washed three times with buffer and then photographed using a Leica DFC300 FX camera (Leica Microsystems, Wetzlar, Germany) and the software application, Leica IM50 v4.0.

For the histological morphology analysis, the skin specimens from back tissues of Sod1 ${ }^{-/}$mice (5 months old) were dissected, fixed overnight in a $20 \%$ formalin neutral buffer solution (Wako Pure Chemical Industries, Ltd, Osaka, Japan), embedded in paraffin, and sectioned on a microtome at $4 \mu \mathrm{m}$ thick by standard techniques. The hematoxylin and eosin staining was performed as described previously [8]. The thickness of the skin tissue was measured using Leica QWin V3 image software (Leica Microsystems). 


\subsection{Quantitative PCR}

The total RNAs from the back skin were extracted with Trizol reagent (Life Technologies Corporation) according to the manufacturer's instructions. The cDNA was synthesized from $1 \mu \mathrm{g}$ of total RNA by reverse transcriptase (ReverTra Ace qPCR RT Master MIX, TOYOBO Osaka, Japan). Real-time PCR was performed on a Mini Opticon ${ }^{\mathrm{TM}}$ (Bio-Rad, Hercules, CA, USA) with SsoAdvanced SYBR Green Supermix (Bio-Rad, Redmond, WA, USA) according to the manufacturer's instructions. The following primers were used for the analysis: $\beta$-actin, forward, 5'-GCCCTAGGCACCAGGGTGTGA-3', and reverse, 5'-TCCTCAGGGGCCACACGCA-3'; Rn18s, forward, 5'-GTAACCCGTTGAACCCCATT-3', and reverse, 5'-CCATCCAATCGGTAGTAGCG-3'; p53, forward, 5'-ACGCTTCTCCGAAGACTGG-3', and reverse, 5'-AGGGAGCTCGAGGCTGATA-3'.

\subsection{Statics}

The statistical evaluations were performed using the two-tailed Student's $t$-test for unpaired values. Any differences between the data were considered to be significant when the $p$ values were less than 0.05 . The data are represented as the means plus or minus the standard deviation.

\section{Conclusions}

Our results revealed that Sodl deficiency induced intracellular $\mathrm{O}_{2}{ }^{--}$accumulation in the cytoplasm and mitochondria resulting in decreased proliferation and increased apoptotic cell death in fibroblasts. Our findings also demonstrated that Sod1 loss triggered the DNA damage response including p53 activation and promoted the mitochondrial dysfunction associated with low mitochondrial membrane potential. These results suggested that both mitochondrial dysfunction and p53 activation can cause the impairment of cell proliferation and the induction of apoptosis in Sod1 $1^{-/}$fibroblasts. Furthermore, antioxidant treatment effectively suppressed the p53 activation and improved the cellular and skin phenotypes caused by the Sod1 deficiency in vitro and in vivo.

\section{Acknowledgments}

This research was supported in part by the Program for the Promotion of Basic Research Activities for Innovative Biosciences (T. Shim.). We would also like to thank Daichi Morikawa, Keiji Kobayashi, Masato Koike, and Kazue Kinoshita from Chiba University for their valuable technical assistance.

\section{Conflict of Interest}

The authors declare no conflict of interest.

\section{References}

1. Finkel, T.; Holbrook, N.J. Oxidants, oxidative stress and the biology of ageing. Nature 2000, 408, 239-247.

2. Ditch, S.; Paull, T.T. The ATM protein kinase and cellular redox signaling: beyond the DNA damage response. Trends Biochem. Sci. 2012, 37, 15-22. 
3. Kumari, U.; Jun, W.Y.; Bay, B.H.; Lyakhovich, A. Evidence of mitochondrial dysfunction and impaired ROS detoxifying machinery in Fanconi Anemia cells. Oncogene 2012, doi:10.1038/onc.2012.583.

4. Rufini, A.; Tucci, P.; Celardo, I.; Melino, G. Senescence and aging: The critical roles of p53. Oncogene 2013, doi:10.1038/onc.2012.640.

5. Okado-Matsumoto, A.; Fridovich, I. Subcellular distribution of superoxide dismutases (SOD) in rat liver: Cu,Zn-SOD in mitochondria. J. Biol. Chem. 2001, 276, 38388-38393.

6. Imamura, Y.; Noda, S.; Hashizume, K.; Shinoda, K.; Yamaguchi, M.; Uchiyama, S.; Shimizu, T.; Mizushima, Y.; Shirasawa, T.; Tsubota, K. Drusen, choroidal neovascularization, and retinal pigment epithelium dysfunction in SOD1-deficient mice: A model of age-related macular degeneration. Proc. Natl. Acad. Sci. USA 2006, 103, 11282-11287.

7. Uchiyama, S.; Shimizu, T.; Shirasawa, T. CuZn-SOD deficiency causes ApoB degradation and induces hepatic lipid accumulation by impaired lipoprotein secretion in mice. J. Biol. Chem. 2006, 281, 31713-31719.

8. Murakami, K.; Inagaki, J.; Saito, M.; Ikeda, Y.; Tsuda, C.; Noda, Y.; Kawakami, S.; Shirasawa, T.; Shimizu, T. Skin atrophy in cytoplasmic SOD-deficient mice and its complete recovery using a vitamin C derivative. Biochem. Biophys. Res. Commun. 2009, 382, 457-461.

9. Nojiri, H.; Saita, Y.; Morikawa, D.; Kobayashi, K.; Tsuda, C.; Miyazaki, T.; Saito, M.; Marumo, K.; Yonezawa, I.; Kaneko, K.; et al. Cytoplasmic superoxide causes bone fragility owing to low-turnover osteoporosis and impaired collagen cross-linking. J. Bone Miner. Res. 2011, 26, 2682-2694.

10. Murakami, K.; Murata, N.; Noda, Y.; Tahara, S.; Kaneko, T.; Kinoshita, N.; Hatsuta, H.; Murayama, S.; Barnham, K.J.; Irie, K.; et al. SOD1 (copper/zinc superoxide dismutase) deficiency drives amyloid $\beta$ protein oligomerization and memory loss in mouse model of Alzheimer disease. J. Biol. Chem. 2011, 286, 44557-44568.

11. Noda, Y.; Ota, K.; Shirasawa, T.; Shimizu, T. Copper/zinc superoxide dismutase insufficiency impairs progesterone secretion and fertility in female mice. Biol. Reprod. 2012, 86, 1-8.

12. Kojima, T.; Wakamatsu, T.H.; Dogru, M.; Ogawa, Y.; Igarashi, A.; Ibrahim, O.M.; Inaba, T.; Shimizu, T.; Noda, S.; Obata, H.; et al. Age-related dysfunction of the lacrimal gland and oxidative stress: Evidence from the $\mathrm{Cu}, \mathrm{Zn}$-superoxide dismutase-1 (Sod1) knockout mice. Am. J. Pathol. 2012, 180, 1879-1896.

13. Elchuri, S.; Oberley, T.D.; Qi, W.; Eisenstein, R.S.; Jackson Roberts, L.; van Remmen, H.; Epstein, C.J.; Huang, T.T.; CuZnSOD deficiency leads to persistent and widespread oxidative damage and hepatocarcinogenesis later in life. Oncogene 2005, 24, 367-380.

14. Muller, F.L.; Song, W.; Liu, Y.; Chaudhuri, A.; Pieke-Dahl, S.; Strong, R.; Huang, T.T.; Epstein, C.J.; Roberts, L.J.; Csete, M.; et al. Absence of $\mathrm{CuZn}$ superoxide dismutase leads to elevated oxidative stress and acceleration of age-dependent skeletal muscle atrophy. Free Radic. Biol. Med. 2006, 40, 1993-2004.

15. Iuchi, Y.; Okada, F.; Onuma, K.; Onoda, T.; Asao, H.; Kobayashi, M.; Fujii, J. Elevated oxidative stress in erythrocytes due to a SOD1 deficiency causes anaemia and triggers autoantibody production. Biochem. J. 2007, 402, 219-227.

16. Huang, T.T.; Yasunami, M.; Carlson, E.J.; Gillespie, A.M.; Reaume, A.G.; Hoffman, E.K.; Chan, P.H.; Scott, R.W.; Epstein, C.J. Superoxide-mediated cytotoxicity in superoxide dismutase-deficient fetal fibroblasts. Arch. Biochem. Biophys. 1997, 344, 424-432. 
17. Brenner, C.; Moulin, M. Physiological roles of the permeability transition pore. Circ. Res. 2012, $111,1237-1247$.

18. Vurusaner, B.; Poli, G.; Basaga, H. Tumor suppressor genes and ROS: Complex networks of interactions. Free Radic. Biol. Med. 2012, 52, 7-18.

19. Shibuya, S.; Kinoshita, K.; Shimizu, T. Handbook of Diet, Nutrition and the Skin, 2nd ed.; Wageningen Academic Publishers: Wageningen, The Netherlands, 2012; pp. 351-366.

20. Muller, F.L.; Liu, Y.; van Remmen, H. Complex III releases superoxide to both sides of the inner mitochondrial membrane. J. Biol. Chem. 2004, 279, 49064-49073.

21. Jang, Y.C.; Liu, Y.; Hayworth, C.R.; Bhattacharya, A.; Lustgarten, M.S.; Muller, F.L.; Chaudhuri, A.; Qi, W.; Li, Y.; Huang, J.Y.; et al. Dietary restriction attenuates age-associated muscle atrophy by lowering oxidative stress in mice even in complete absence of CuZnSOD. Aging Cell 2012, 11, 770-782.

22. Kruse, J.P.; Gu, W. Modes of p53 regulation. Cell 2009, 137, 609-622.

23. Gajjar, M.; Candeias, M.M.; Malbert-Colas, L.; Mazars, A.; Fujita, J.; Olivares-Illana, V.; Fåhraeus, R. The p53 mRNA-Mdm2 interaction controls Mdm2 nuclear trafficking and is required for p53 activation following DNA damage. Cancer Cell 2012, 21, 25-35.

24. Hamard, P.J.; Manfredi, J.J. Mdm2's dilemma: To degrade or to translate p53? Cancer Cell 2012, $21,3-5$.

25. Mbaya, E.; Oulès, B.; Caspersen, C.; Tacine, R.; Massinet, H.; Pennuto, M.; Chrétien, D.; Munnich, A.; Rötig, A.; Rizzuto, R.; et al. Calcium signalling-dependent mitochondrial dysfunction and bioenergetics regulation in respiratory chain Complex II deficiency. Cell Death Differ. 2010, 17, 1855-1866.

26. Jiang, P.; Du, W.; Mancuso, A.; Wellen, K.E.; Yang, X. Reciprocal regulation of p53 and malic enzymes modulates metabolism and senescence. Nature 2013, 493, 689-693.

27. Tyner, S.D.; Venkatachalam, S.; Choi, J.; Jones, S.; Ghebranious, N.; Igelmann, H.; Lu, X.; Soron, G.; Cooper, B.; Brayton, C.; et al. p53 mutant mice that display early ageing-associated phenotypes. Nature 2002, 415, 45-53.

28. Gannon, H.S.; Donehower, L.A.; Lyle, S.; Jones, S.N. Mdm2-p53 signaling regulates epidermal stem cell senescence and premature aging phenotypes in mouse skin. Dev. Biol. 2011, 353, 1-9.

29. Peterkofsky, B. Ascorbate requirement for hydroxylation and secretion of procollagen: Relationship to inhibition of collagen synthesis in scurvy. Am. J. Clin. Nutr. 1991, 54, S1135-S1140.

30. Murakami, K.; Murata, N; Ozawa, Y.; Kinoshita, N.; Irie, K.; Shirasawa, T.; Shimizu, T. Vitamin $\mathrm{C}$ restores behavioral deficits and amyloid- $\beta$ oligomerization without affecting plaque formation in a mouse model of Alzheimer's disease. J. Alzheimers Dis. 2011, 26, 7-18.

31. Kalyanaraman, B.; Darley-Usmar, V.; Davies, K.J.; Dennery, P.A.; Forman, H.J.; Grisham, M.B.; Mann, G.E.; Moore, K.; Roberts, L.J.; Ischiropoulos, H. Measuring reactive oxygen and nitrogen species with fluorescent probes: Challenges and limitations. Free Radic. Biol. Med. 2012, 52, 1-6.

(C) 2013 by the authors; licensee MDPI, Basel, Switzerland. This article is an open access article distributed under the terms and conditions of the Creative Commons Attribution license (http://creativecommons.org/licenses/by/3.0/). 